\title{
Design and Preparation of Cross-Linked Polystyrene Nanoparticles for Elastomer Reinforcement
}

\author{
Ming Lu, ${ }^{1}$ Jianjun Zhou, ${ }^{1}$ Liansheng Wang, ${ }^{1}$ Wei Zhao, ${ }^{1}$ Yonglai Lu, ${ }^{1}$ Liqun Zhang, ${ }^{1,2}$ \\ and Yakang $\mathrm{Liu}^{3}$ \\ ${ }^{1}$ The Key Laboratory for Nanomaterials of Ministry of Education, Beijing University of Chemical Technology, Beijing 100029, China \\ ${ }^{2}$ The Key Laboratory of Beijing City for Preparation and Processing of Novel Polymer Materials, \\ Beijing University of Chemical Technology, Beijing 100029, China \\ ${ }^{3}$ Department of Polymer Science, Beijing University of Chemical Technology, Beijing 100029, China
}

Correspondence should be addressed to Liqun Zhang, zhanglq@mail.buct.edu.cn

Received 31 October 2009; Revised 1 February 2010; Accepted 31 March 2010

Academic Editor: Gaurav Mago

Copyright () 2010 Ming Lu et al. This is an open access article distributed under the Creative Commons Attribution License, which permits unrestricted use, distribution, and reproduction in any medium, provided the original work is properly cited.

Cross-linked polystyrene (PS) particles in a latex form were synthesized by free radical emulsion polymerization. The nano-PSfilled elastomer composites were prepared by the energy-saving latex compounding method. Results showed that the PS particles took a spherical shape in the size of 40-60 nm with a narrow size distribution, and the glass-transition temperature of the PS nanoparticles increased with the cross-linking density. The outcomes from the mechanical properties demonstrated that when filled into styrene-butadiene rubber (SBR), nitrile-butadiene rubber (NBR), and natural rubber (NR), the cross-linked PS nanoparticles exhibited excellent reinforcing capabilities in all the three matrices, and the best in the SBR matrix. In comparison with that of the carbon black filled composites, another distinguished advantage of the cross-linked PS particles filled elastomer composites was found to be light weight in density, which could help to save tremendous amount of energy when put into end products.

\section{Introduction}

Most widely applied elastomer materials, due to the weaknesses in modulus and strength, usually require some kind of reinforcement before putting into use. As this case stands, great parts of the rubber products are actually composites made of the elastomeric matrix and some kind of fillers as well as some other curatives. And the filler, especially the reinforcing filler, plays an important role in determining the performance of the filled rubber compounds [1-9].

In the rubber industry, many types of reinforcing agents have already been developed; carbon black and silica are the ones that are commonly used. These conventional fillers are usually solid powders. Though being very effective in reinforcing, they also show up some drawbacks. As the result of the strong filler-filler interactions and weak filler-rubber interactions, it takes great energy and efforts to blend the powdered fillers with the high-viscous elastomer matrix in a mechanical blender. What's worse, because of the poor compatibility with the rubber matrix, there is a tendency for the fillers to aggregate forming a strong filler network which may do harm to the dispersion of the fillers and the performance of the composites as well.

For further enhancing the performances of the filled elastomer composites, we had raised a concept of the ideal fillers for elastomer reinforcement $[6,10]$. To be such an ideal filler, it should possess some distinguishing features: (1) size in the nanoscale, so as to provide excellent reinforcement to the elastomer matrix; (2) spherical shape, helping to reduce the processing-viscosity of the filled rubber; (3) easy access to a fine dispersion in the rubber matrix, holding back filler aggregation and weakening the filler network; (4) some chemical activity on the surface, providing certain chemical interaction between the filler and the matrix; (5) lower density, reducing the dynamically driving energy of the filled elastomer composites; (6) lower price. However, the conventional fillers, like carbon black and silica, do not possess all these features. 
In our opinion, polymeric fillers may open a door for the development of some novel elastomer reinforcing agents. Different from the natural fillers which have taken certain structure and surface properties as born, the polymeric fillers can be designed and synthesized as the designer's intention. We can not only take the structure of the fillers in control, but also make some needed modification to the fillers for adjusting the filler-rubber interactions.

Few literatures reported some work in rubber academy using some polymeric filler, usually some rigid emulsion particles like polystyrene nano-particles, as the model fillers for the investigations on the mechanisms of elastomer reinforcement [11-14]. And rubber industry also started to show some interests in developing novel elastomer reinforcing agents from polymeric fillers. Zheng et al. [15] from Goodyear Tire \& Rubber Company have synthesized some model hairy nano-particles of cross-linked polystyrene cores and polybutadiene brushes, and Wang et al. [16] from Bridgestone Americas have prepared various core-shell nanoparticles with different shapes and sizes. They both thought the polymeric fillers capable as a novel elastomer reinforcing agents. But the end products of the polymeric fillers in their work were also in a powder state, and to the best of our knowledge, aggregates of the filler particles would inevitably come into being as the result of the flexible, rubber-like polybutadiene shell that they both had in their powdered products. When preparing the rubber compound mixture, they had to take great extra energy and efforts to disperse these polymeric fillers into the high-viscous rubber matrix again.

Our work was carried out in an attempt to provide a commercially viable method to prepare ideal fillers for elastomer reinforcement. Considering that most rubber types in use have their latex forms, we intended to prepare a kind of latex-formed polymeric fillers for the reinforcement of the elastomeric matrices. In this work, styrene was chosen as the monomer due to easy access and its compatibility with the commonly used elastomer matrices such as styrene-butadiene rubber (SBR) and nitrile-butadiene rubber (NBR). Divinyl benzene (DVB) was introduced into the polymerization system as the cross-linking agent for further enhancing the glass-transition temperature $\left(T_{g}\right)$ and stiffness of the polymer particles in case of possible applications in hot environment. Emulsion radical polymerization was made as the synthesis technique to prepare such latex-formed polymeric fillers.

In our work, the cross-linked polystyrene (PS) filled elastomer composites were prepared by the energy-saving latex compounding method (LCM). As a water-mediating compounding method, LCM [17-19] greatly reduced the viscosity of both the filler system and the bulk matrix system, thus saving tremendous amount of energy and resulting in better dispersion of the fillers.

A soft shell (like polyisoprene) over the particles, composed of some polymer compatible with the elastomer matrix, helping to adjust the filler-rubber interactions, has also been designed. The work covering that part will be discussed in another paper. In this work, we focused on the PS particles themselves. The influence of cross-linking density on the properties of the cross-linked polystyrene particles, and the reinforcement of the spherical PS nanoparticles to the elastomer matrices, were investigated respectively.

\section{Experiment}

2.1. Materials. Styrene (St) was purchased from Fuchen Chemical Agent Co., Ltd (Tianjin). Divinyl benzene (DVB) was supplied by Jinke Fine Chemical Agent (Tianjin) Co., Ltd. And sodium hydrogen carbonate $\left(\mathrm{NaHCO}_{3}\right)$ was supplied by Shanghai Linfeng Chemical Agent Co., Ltd., China. Ammonium persulfate (APS) was purchased from Beijing Chemical Agent Co., Ltd., China. Polyoxyethylene octylphenol ether (emulsifier OP-10) was supplied by Vason Chemical Agent Co., Ltd (Tianjin). Sodium dodecyl sulfonate (SDS) was a commercial product of Beijing Yili Fine Chemical Co., Ltd. Anhydrous calcium chloride $\left(\mathrm{CaCl}_{2}\right)$ was a product from Beijing Beihua Fine Chemicals Co., Ltd. Styrene-butadiene rubber (manufacture brand SBR1502) and its latex were supplied by Jilin petrochemical Co. China. Nitrile-butadiene rubber latex (manufacture brand LHN-212), with acrylonitrile content of $26 \mathrm{wt} \%$, was a product from Lanzhou petrochemical Co. China. Natural rubber latex was purchased from Beijing latex products factory (China). All other reagents for rubber compounds are commercial products.

2.2. Synthesis of the Cross-Linked Polystyrene. A four-necked flask equipped with a stirrer, a reflux condenser, a dropping funnel and a thermometer, was first charged with appropriate emulsifier SDS/OP-10 and deionized water. Start the stirrer at an appropriate speed for a while until an evenly blended mixture was obtained. The batch was then charged with certain amount of monomers of styrene and DVB at given ratio. Following another 30-min's emulsification, the batch was heated to $70^{\circ} \mathrm{C}$. When temperature got stable, polymerization was initiated by adding APS water solution. $\mathrm{NaHCO}_{3}$ water solution was added in order to adjust the $\mathrm{pH}$ value of the latex equal to 7 . The batch temperature of $70^{\circ} \mathrm{C}$ was maintained during the entire polymerization process. Remaining monomers had been added by dripping since 30 minutes after the initiation. Several hours later, the emulsion polymerization reaction completed. And the crosslinked polystyrene latex was obtained.

2.3. Preparation of the Filled Composites. The PS-filled elastomer composites were prepared by LCM. The crosslinked polystyrene latex and rubber latex were mixed at given ratio by a mechanical stirrer for a period of time. After that, the even mixture was poured into the $\mathrm{CaCl}_{2}$ water solution in stirring for coagulation. The master batch was washed several times before drying in an air oven at $50^{\circ} \mathrm{C}$ for 24 hours. All the ingredients of curatives (seen in Tables 1 and 2 ) were added in a two-roll miller. The master batch was then vulcanized at certain temperature $\left(150^{\circ} \mathrm{C}\right.$ for $\mathrm{SBR}, 160^{\circ} \mathrm{C}$ for $\mathrm{NBR}$, and $145^{\circ} \mathrm{C}$ for NR) for a period of time of $T_{90}$ under the pressure of $15 \mathrm{MPa}$. 
TABLE 1: Recipe for SBR and NR composites.

\begin{tabular}{lc}
\hline Ingredients & Loading $\left(\mathrm{phr}^{\mathrm{a}}\right)$ \\
\hline $\mathrm{SBR}$ or NR & 100 \\
$\mathrm{PS}$ & variation \\
\hline $\mathrm{ZnO}$ & 3.0 \\
Stearic Acid (SA) & 1.0 \\
Accelerator $\mathrm{D}^{\mathrm{b}}$ & 0.5 \\
Accelerator $\mathrm{DM}^{\mathrm{c}}$ & 0.5 \\
Accelerator $\mathrm{TT}^{\mathrm{d}}$ & 0.2 \\
Antioxidant $4010 \mathrm{NA}^{\mathrm{e}}$ & 1.0 \\
Sulfur & 2.0 \\
\hline
\end{tabular}

${ }^{a}$ parts per hundred rubber parts in weight; ${ }^{b}$ Diphenyl guanideine; ${ }^{c} 2,2^{\prime}$ dibenzothiazole disulfide; ${ }^{\mathrm{d}}$ Tetramethylthiuram disulfide; ${ }^{\mathrm{e}} \mathrm{N}$-isopropyl$N^{\prime}$-phenyl-p-phenylenediamine.

TABLE 2: Recipe for NBR composites.

\begin{tabular}{lc}
\hline Ingredients & Loading (phr) \\
\hline $\mathrm{NBR}$ & 100 \\
$\mathrm{PS}$ & 30 \\
\hline ZnO & 5.0 \\
Stearic Acid (SA) & 1.0 \\
Accelerator DM & 1.0 \\
Antioxidant 4010NA & 2.0 \\
Sulfur & 1.5 \\
\hline
\end{tabular}

2.4. Characterization Techniques. The particle size and the particle size distribution was measured by Zetasizer Nano ZS particle analyzer (UK Malvern Instruments Ltd.) in the means of dynamic light scattering (DLS). The SEM and TEM images were obtained by S-4700 Scanning Electron Microscope (Japan Hitachi Co. Ltd.) and H-800 Transmission Electron Microscope (Japan Hatachi Co. Ltd.), respectively. DSC tests were carried out with DSC-2C differential scanning calorimeter (US Perkin-elmer Co. Ltd.) in $\mathrm{N}_{2}$ gas flow with a heating rate of $10^{\circ} \mathrm{C} / \mathrm{min}$. The tensile tests were conducted with dog-bone-shape samples on an Instron-type tensile testing machine at a speed of $500 \mathrm{~mm} / \mathrm{min}$ according to ASTM D412. Measurement of dynamical mechanical rheology was performed with the rheometer RPA 2000 (Alpha Technologies, USA). Shore A hardness of the vulcanizates were measured according to ASTM D2240, using a XY-1 type A durometer (No. 4 Chemical Machinery Plant of Shanghai Chemical Equipment Co. Ltd., Shanghai, China), and three different spots of the sample (over $6 \mathrm{~mm}$ in thickness) were measured to give the average.

\section{Results and Discussion}

3.1. Size and Morphology. With semicontinuing feeding operation in starving state, the cross-linked polystyrene particles were prepared in an emulsion polymerization system. Products were analyzed with Zetasizer Nano ZS particle analyzer and TEM. The results showed that the crosslinked polystyrene took a spherical shape in the size of 40$60 \mathrm{~nm}$ with a narrow distribution, as seen in Figure 1.

The nanosized particles are essential to the reinforcement of the elastomer matrix [20-23]. With high specific surface area, they provide sufficient interphase for the filler-rubber interactions, and make the orientation of the elastomer molecular chain segments possible in the stretching process [24]. The elastomer molecules stuck to the filler particles due to the filler-rubber interactions; when in tension, the elastomer molecules might slip along the surface of the filler particles; after that, the chains stuck back to the filler particles again. In further tension, the stick-slip process went round and round, resulting in the orientation of the elastomer molecular chain segments. Between the neighboring filler particles, the oriented segments at the same length became to bear the outer force simultaneously. And as a result, the inside details turned out to be higher modulus of the sample shown as strain hardening in the stress-strain curve.

3.2. Influence of the Cross-Linking Density. PS particles with different cross-linking densities were prepared by varying the consumption of DVB at $0 \mathrm{wt} \%, 10 \mathrm{wt} \%, 20 \mathrm{wt} \%$, and $30 \mathrm{wt} \%$ of the styrene loading. With the increase of DVB consumption, the cross-linking density of the particles went higher. As results, the mobility of the polystyrene molecules decreased; the glass-transition temperature of the crosslinked polystyrene went up; and the particles achieved higher modulus. All the outcomes above could make the cross-linked PS particles more competent when in hot environment applications.

As seen in Figure 2, the glass-transition temperature of the PS particles increased with DVB consumption. Though theoretically, an access to higher $T_{g}$ of the PS particles was possible with even higher consumption of DVB, $20 \mathrm{wt} \%$ would be a better choice, when we take the influence on the stability of the emulsion system into consideration.

In our experiments, when filtering the PS latex obtained after the emulsion polymerization, we found that the gel part in the PS latex increased with higher consumption of DVB. This could attribute to the cross-linking between the latex particles. As known, DVB has two functional groups of vinyl, which makes it a cross-linker in the polymerization. It linked not only the molecules in a latex particle when diffused into the latex particles but also the latex particles themselves when initiated outside by free radicals. At higher DVB consumption, the chances that the cross-linker was initiated outside the latex particles increased, and as a result, more latex particles were jointed together. Subsequently, the jointed latex particles turned out to be the loss in the stability of the emulsion polymerization system.

\subsection{Reinforcement to Elastomer Matrices}

3.3.1. With PS Fillers of Different Cross-Linking Densities. Composites filled with PS fillers of different cross-linking densities were prepared in order to investigate the influence of the cross-linking density on the reinforcing performances 


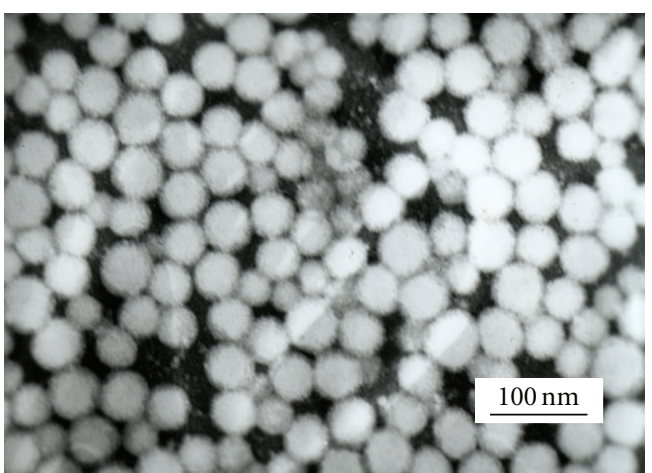

(a)

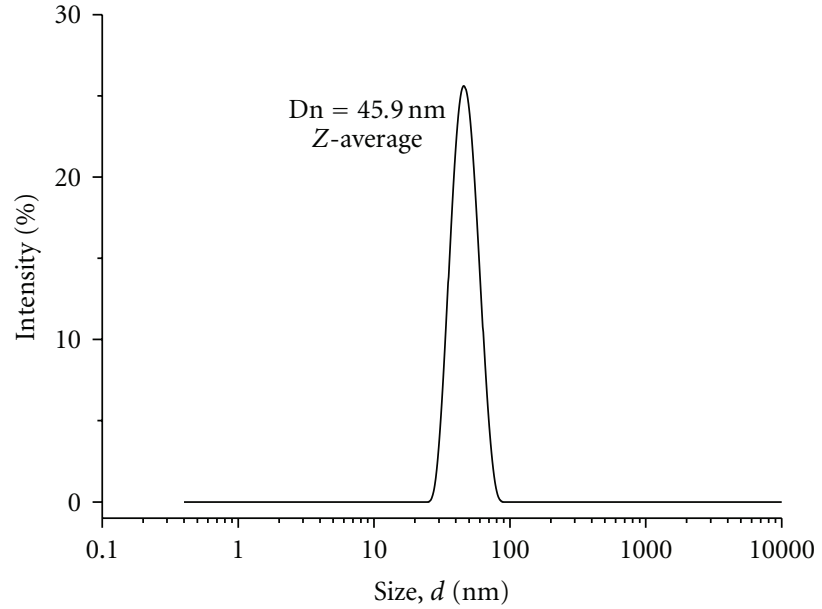

(b)

FIGURE 1: Morphology, size, and size distribution of cross-linked PS particles. (a) is the TEM image of cross-linked PS particles with DVB consumption of $20 \mathrm{wt} \%$ of styrene loading; (b) is the result of the same sample from the DLS test.



FIGURE 2: DSC curves of the PS particles with varied DVB consumption.

of the PS particles. The composites of PS-filled SBR were vulcanized by a low-temperature curing system of benzyl peroxide (BPO) at $95^{\circ} \mathrm{C}$, so as to prevent possible damage to the morphology of the PS particles when in high temperature like in the sulfur-curing system.

It was indicated in Table 3 that there were significant improvements in mechanical properties of PS-filled SBR nanocomposites, compared with those of the neat SBR. With higher DVB consumption, the tensile strength of the composites improved, while the hardness, permanent set, and tear strength of the composites varied a little. It is worth a special notice that stress at $300 \%$ elongation exhibited an extraordinary decrease when with higher DVB consumption. But the results from the sample of $30 \mathrm{wt} \% \mathrm{DVB}$ consumption didn't keep the law as the other samples did. Unfortunately, we failed to find a suitable explanation for this.

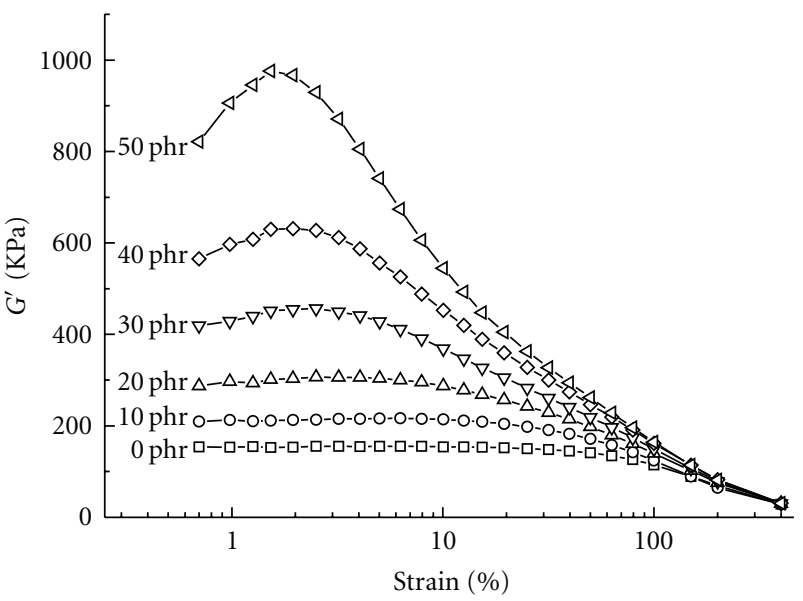

Figure 3: Strain amplitude dependence of storage modulus $\left(G^{\prime}\right)$ of the PS-filled SBR composites.

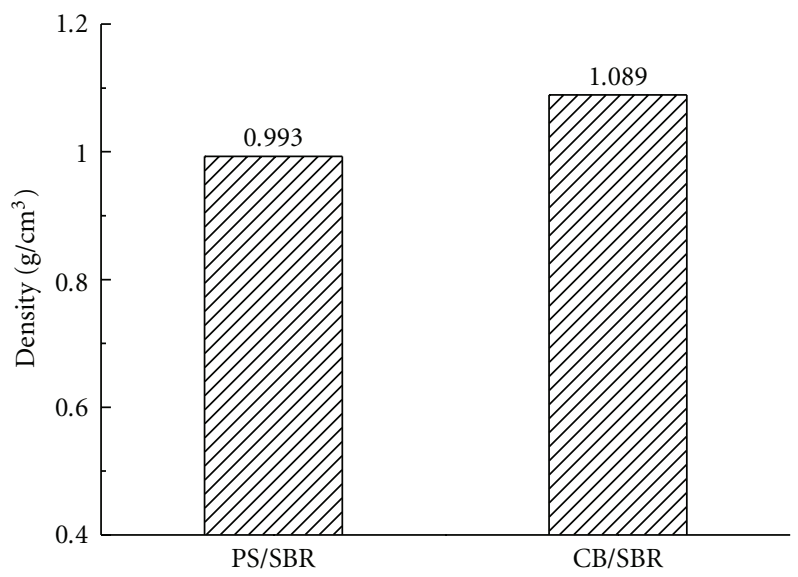

FIGURE 4: Comparison in density between PS-filled SBR and carbon black filled SBR. 


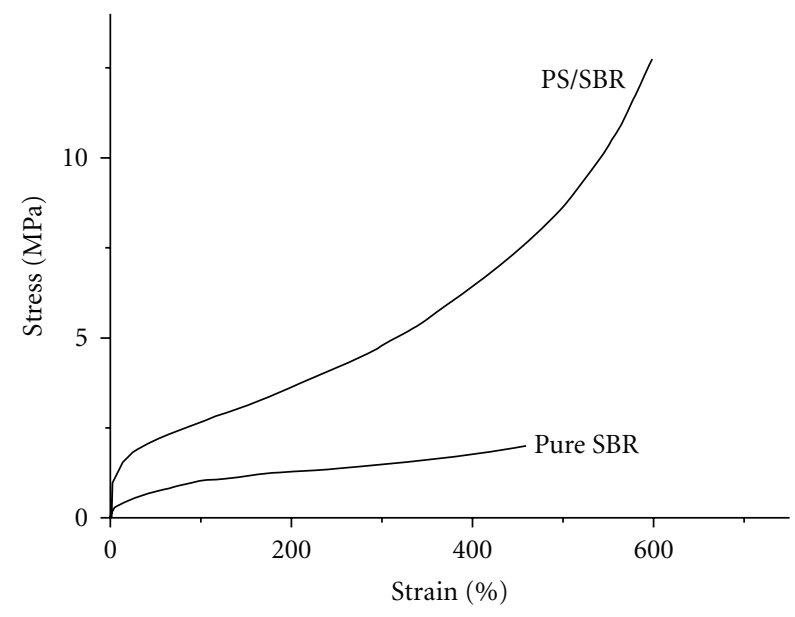

(a)

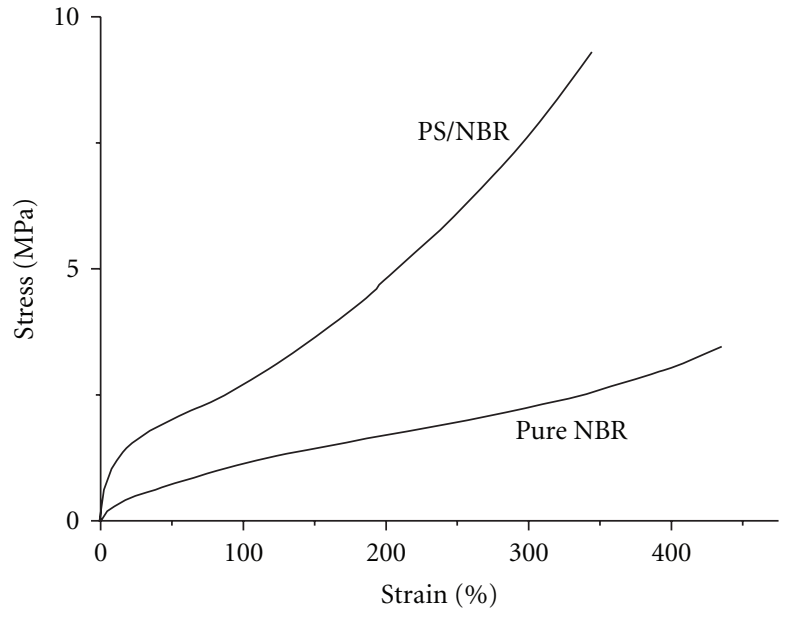

(b)



(c)

FIGURE 5: Reinforcing behavior of the cross-linked PS in different matrices with a loading of $30 \mathrm{phr}$. (a)-(c) represented the performances in SBR, NBR, and NR, respectively.

TABLE 3: Influence of DVB consumption on the mechanical properties of PS-filled SBR nanocomposites.

\begin{tabular}{cccccccc}
\hline \multirow{2}{*}{ Samples } & $\begin{array}{c}\text { Stress at 300\% } \\
\text { Elongation/MPa }\end{array}$ & $\begin{array}{c}\text { Tensile } \\
\text { Strength/MPa }\end{array}$ & $\begin{array}{c}\text { Elongation at } \\
\text { Break/\% }\end{array}$ & $\begin{array}{c}\text { Permanent } \\
\text { Set/\% }\end{array}$ & $\begin{array}{c}\text { Shore A } \\
\text { Hardness/ }\end{array}$ & $\begin{array}{c}\text { Tear Strength } \\
/ \mathrm{KN} / \mathrm{m}\end{array}$ \\
\hline \multirow{6}{*}{ Neat SBR } & 1.4 & 1.5 & 327 & 0 & 46 & 7 \\
\hline \multirow{3}{*}{ PS/SBR } & DVB 0\% & 3.3 & 9.3 & 535 & 20 & 70 & 20 \\
& DVB 10\% & 2.3 & 12.5 & 607 & 16 & 70 & 66 \\
& DVB 20\% & 2.2 & 15.9 & 630 & 14 & 10 & 65 \\
\hline
\end{tabular}

Note that the loading of PS filler was $20 \mathrm{phr}$; the cross-linked PS filler were prepared with DVB consumption of $0 \mathrm{wt} \%, 10 \mathrm{wt} \%, 20 \mathrm{wt} \%$, and $30 \mathrm{wt} \%$ of the styrene loading. The composites were cured with $4 \mathrm{phr}$ benzyl peroxide (BPO) at $95^{\circ} \mathrm{C}$ for 120 minutes.

What brought about these changes was the increasing cross-linking density. With higher DVB consumption, the cross-linking density of the PS fillers increased, and thus the mobility of the molecules decreased, which made the diffusion more difficult at the interfaces between the fillers and the matrix. As a result, the interactions between the
SBR matrix and the PS fillers weakened; the stress at given elongation decreased.

This relatively weak filler-rubber interaction can also explain why at present, the stress at given elongation of the cross-linked polystyrene filled rubber composites didn't match those of the carbon black filled rubber at the same 


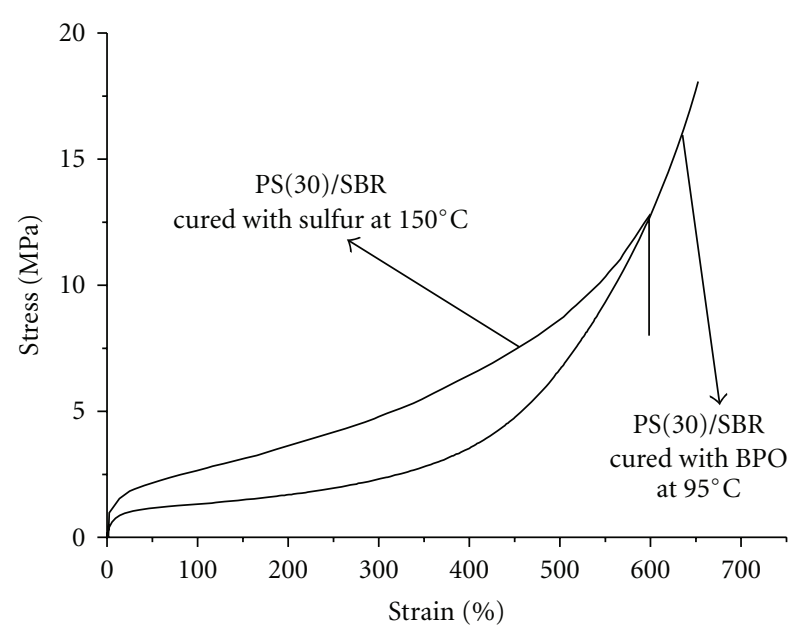

FIGURE 6: Comparison in mechanical performances of PS(30)/SBR composites with varied curing systems.

loading. Preparation of such a kind of polymeric filler with a core-shell structure was a solution for further enhancing the properties. A shell of some polymer of good compatibility with the elastomer matrix, like polyisoprene, would work to ameliorate the interaction between the rubber matrix and the polymeric fillers so as to improve the mechanical properties of the filled rubber composites. We will report the work covering this part in another paper.

3.3.2. With PS Fillers at Varied Loadings. The cross-linked polystyrene particles prepared with $20 \mathrm{wt} \%$ DVB consumption was chosen due to better performances in glasstransition temperature, emulsion polymerization process, and properties of the filled SBR composites. Mechanical properties of the cross-linked PS-filled SBR composites with filler loading of $0 \mathrm{phr}, 10 \mathrm{phr}, 20 \mathrm{phr}, 30 \mathrm{phr}, 40 \mathrm{phr}$, and $50 \mathrm{phr}$ were tested, respectively.

As shown in Table 4, the stress at 300\% elongation increased with filler loading, but it was still relatively low when compared with that of the carbon black filled samples at the same loading. The tensile strength improved remarkably with the increase of the filler loading at first and then stayed at a level with the loading of $30 \mathrm{phr}$ and higher; the hardness, permanent set and tear strength increased with the filler loading. Higher loading of the PS fillers led to stronger filler network, as shown in Figure 3 that the Payne effect [25] became more enormous when filler loading increased. And because of stronger filler network at higher loading, hardness of the samples showed an increase by the numbers.

A distinguishing advantage of the polymeric fillers filled elastomer composites was the light weight, which could contribute to save tremendous amount of energy when made into products. Therefore, densities of the samples with varied filler loadings were tested. Results were listed in Table 5. A comparison in density between the PS-filled SBR and carbon black filled SBR was made with the same loading of $30 \mathrm{phr}$ (seen in Figure 4), which again revealed the advantage of the PS-filled SBR composites in weight. The density of PSfilled SBR composites with a loading of $50 \mathrm{phr}$ was no more than $1.000 \mathrm{~g} / \mathrm{cm}^{3}$, proving that the PS-filled SBR composites was superior in weight to the composites filled with those conventional fillers.

3.3.3. In Several Elastomer Matrices. Reinforcement of the cross-linked polystyrene particles to the elastomeric matrices of styrene-butadiene rubber (SBR), nitrile-butadiene rubber (NBR), and natural rubber (NR) was investigated with a filler loading of $30 \mathrm{phr}$. As long as the PS particles had been cross-linked, high-temperature vulcanization system of sulfur was employed to prepare the cured PS-filled elastomer composites with an attempt to promote molecule diffusion thus strengthening the filler-rubber interactions by heating.

As shown in Figure 5 and Table 6, remarkable improvements in mechanical properties were there. Tensile strength of the PS-filled NR composites was blighted. We speculated the reason could be that the strain-induced crystallization of NR was affected when the PS particles were introduced in. Except that, comparing with the three pure elastomer matrices, composites filled with the cross-linked PS particles exhibited great enhancement in stress at given elongation, tensile strength, and tear strength as well. Further more, the enhancement in the PS-filled SBR composite was very remarkable due to the good compatibility of the PS particles with the SBR matrix.

As we mentioned earlier, nano-particles provided much more interface for the stick-slip processes of the elastomer molecules, compared with the conventional microparticles. The oriented clusters of the elastomer molecules brought about by the stick-slip processes were the most important reason for the enhanced reinforcing performances of the elastomer composites. This could also explain why filled composites had higher percentage elongation than the pure matrix. In the cured neat elastomer, the cross-linking bonds randomly distributed in the molecules; the chain length between two cross-linking bonds varied from each other. Because of the chemical bonding, molecules were impossible to slip at the cross-linking bonds; thus no oriented clusters of elastomer molecules were there. In the filled composites, besides the chemical cross-links, the physical adhesion between the filler particles and the elastomer matrix functioned as supplemented physical cross-links. Elastomer molecules could easily debound and rebound to the filler surface, and this made the stick-slip process possible, resulting in improved strength and higher percentage elongation.

Compared with the results of the PS-filled SBR composites cured by BPO, the sulfur-cured PS-filled SBR composites exhibited stronger filler-rubber interactions, to be specific, higher stress at given elongation and hardness, as illustrated in Figure 6. But in the PS-filled SBR composites cured with $\mathrm{BPO}$, tensile strength was higher, and strain-hardening was observed in the stress- strain curve at large deformation.

The different morphologies of the PS-filled SBR, NBR, and NR elastomeric matrices at the tensile fracture surface were shown in Figure 7. In SBR and NBR, a fine distribution 


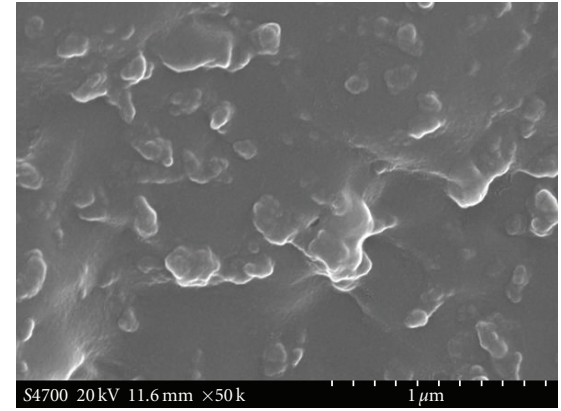

(a)

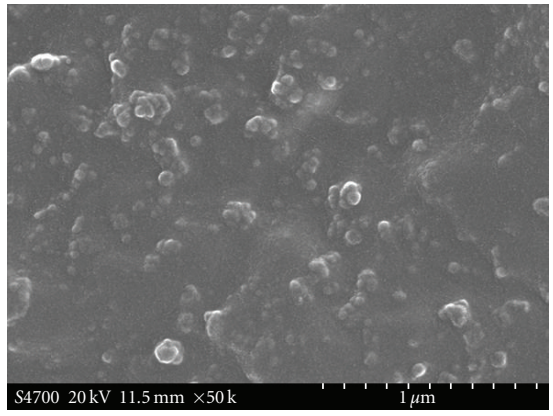

(b)

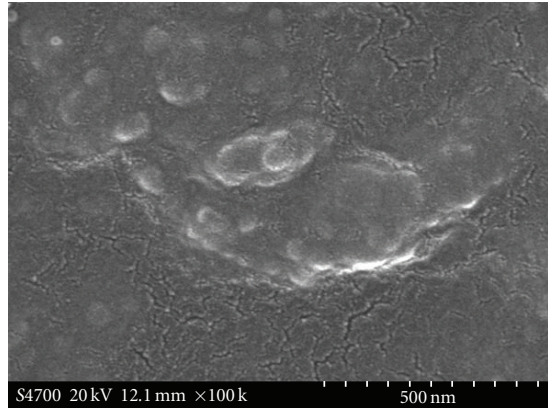

(c)

FIGURE 7: Morphology of the PS particles in different elastomeric matrices (tensile fracture surface). (a)-(c) represented the SEM images of the PS-filled SBR, NBR, and NR composites, respectively.

TABLE 4: Mechanical properties of the cross-linked PS-filled SBR composites with varied loadings.

\begin{tabular}{|c|c|c|c|c|c|c|}
\hline Samples & $\begin{array}{c}\text { Stress at } 300 \% \\
\text { Elongation/MPa }\end{array}$ & $\begin{array}{c}\text { Tensile } \\
\text { Strength/MPa }\end{array}$ & $\begin{array}{c}\text { Elongation at } \\
\text { break } / \%\end{array}$ & Permanent Set/\% & $\begin{array}{c}\text { Shore A } \\
\text { Hardness/ }^{\circ}\end{array}$ & $\begin{array}{c}\text { Tear } \\
\text { Strength/KN/m }\end{array}$ \\
\hline Neat SBR & 1.4 & 1.5 & 327 & 0 & 46 & 7 \\
\hline $\mathrm{PS}(10) / \mathrm{SBR}$ & 1.9 & 10.7 & 581 & 10 & 58 & 16 \\
\hline $\mathrm{PS}(20) / \mathrm{SBR}$ & 2.2 & 14.5 & 623 & 16 & 65 & 22 \\
\hline $\mathrm{PS}(30) / \mathrm{SBR}$ & 2.3 & 17.6 & 652 & 18 & 72 & 28 \\
\hline $\mathrm{PS}(40) / \mathrm{SBR}$ & 2.4 & 18.0 & 649 & 24 & 77 & 31 \\
\hline $\mathrm{PS}(50) / \mathrm{SBR}$ & 2.6 & 17.7 & 644 & 26 & 82 & 36 \\
\hline
\end{tabular}

Note that All samples were cured with $4 \mathrm{phr}$ benzyl peroxide (BPO) at $95^{\circ} \mathrm{C}$ for 120 minutes.

TABle 5: Density of the PS-filled SBR composites.

\begin{tabular}{lc}
\hline Samples & Density/ $\left(\mathrm{g} / \mathrm{cm}^{3}\right)$ \\
\hline Neat SBR & 0.958 \\
PS(10)/SBR & 0.978 \\
PS(20)/SBR & 0.985 \\
PS(30)/SBR & 0.993 \\
PS(40)/SBR & 0.996 \\
PS(50)/SBR & 0.998 \\
\hline
\end{tabular}

of the PS particles in the matrices was observed, while in $\mathrm{NR}$, there was a severe aggregation of the PS particles. In addition, over exposure to the high-energy electron beams during the longer-time exploring on the sample surface caused some cracking in the elastomer matrix, as observed in Figure 7(c).

It was the difference in the distribution of the PS particles that resulted in the diverse performances of the filled composites in the mechanical properties. Besides, PS particles in the SBR matrix possessed a rougher surface after break compared with those in the NBR matrix, as could be seen from Figures 7(a) and 7(b), which divulged the difference in filler-rubber interaction in these two composites that the PS particles had a better compatibility and stronger interaction with the SBR matrix.

\section{Conclusion}

Cross-linked polystyrene were prepared by free radical emulsion polymerization; the PS particles took a spherical shape in the size of $40-60 \mathrm{~nm}$ with a narrow distribution. The cross-linked PS particles exhibited excellent reinforcement to the polar and nonpolar elastomeric matrix such as SBR, NBR, and NR. But tensile strength of the PS-filled NR nanocomposites showed up deteriorated somehow. With the increase of filler loading, the mechanical properties of the composites gained remarkable enhancement. Particularly in the SBR matrix, the cross-linked polystyrene particles had good compatibility and strong interactions with the rubber matrix, therefore, resulting in a dramatic improvement in mechanical properties.

With the increase of the cross-linking density, the crosslinked PS spherical particles were provided with higher glass-transition temperature and thus the capability for hot environment applications, but less stability in the emulsion radical polymerization system. In compounds, the fillerrubber interactions of the PS-filled SBR composites weakened with the cross-linking density; however, in the hightemperature vulcanization system of sulfur, the filler-rubber interactions were improved after heated.

As a distinguishing advantage of the polymeric fillers, the cross-linked PS particles filled elastomer composites were superior to those filled with conventional fillers in weight and density. 
TABLE 6: Mechanical properties of the cross-linked PS-filled SBR, NBR, and NR nanocomposites.

\begin{tabular}{lccccccc}
\hline Samples & $\begin{array}{c}\text { Shore A } \\
\text { Hardness }\end{array}$ & $\begin{array}{c}\text { Stress at 100\% } \\
\text { Elongation/MPa }\end{array}$ & $\begin{array}{c}\text { Stress at 300\% } \\
\text { Elongation/MPa }\end{array}$ & $\begin{array}{c}\text { Tensile } \\
\text { Strength/MPa }\end{array}$ & $\begin{array}{c}\text { Elongation at } \\
\text { Break/\% }\end{array}$ & $\begin{array}{c}\text { Permanent } \\
\text { Set/\% }\end{array}$ & $\begin{array}{c}\text { Tear } \\
\text { Strength/KN/m }\end{array}$ \\
\hline Pure SBR & 48 & 1.1 & 1.5 & 2.0 & 461 & 4 & 11 \\
PS (30)/SBR & 81 & 2.7 & 4.8 & 12.9 & 601 & 36 & 39 \\
\hline Pure NBR & 55 & 1.2 & 2.2 & 3.5 & 438 & 0 & 16 \\
PS(30)/NBR & 80 & 2.7 & 7.6 & 9.3 & 345 & 12 & 33 \\
\hline Pure NR & 35 & 0.7 & 1.6 & 28.3 & 801 & 16 & 30 \\
PS(30)/NR & 75 & 1.9 & 3.9 & 19.7 & 650 & 56 & 76 \\
\hline
\end{tabular}

Note that filler loading was $30 \mathrm{phr}$, all samples were cured with sulfur.

\section{Acknowledgment}

This work was supported by National Science Fund for Distinguished Young Scholars (50725310), China. We would like to express our appreciation to them.

\section{References}

[1] J. E. Mark and D. W. Schaefer, "Polymer-based molecular composites," in Proceedings of the Symposium on Materials Research Society, vol. 171, p. 51, Pittsburgh, Pa, USA, 1190.

[2] G. Kraus, "Reinforcement of elastomers by carbon black," Rubber Chemistry and Technology, vol. 51, no. 2, pp. 297-321, 1978.

[3] G. Allen, "Two worlds of rubber technology-new products, new properties," Plastics and Rubber, vol. 1, p. 38, 1976.

[4] A. R. Payne and R. E. Whittaker, "Reinforcement of rubber with carbon black," Composites, vol. 1, no. 4, pp. 203-214, 1970.

[5] L. Bokobza, "The reinforcement of elastomeric networks by fillers," Macromolecular Materials and Engineering, vol. 289, no. 7, pp. 607-621, 2004.

[6] L. Zhang and D. Jia, "The nano-reinforcing technique and science of rubber," in Proceedings of the Symposium of International Rubber Conference, p. 46, Beijing, China, 2004.

[7] J. E. Mark, R. Abou-Hussein, T. Z. Sen, and A. Kloczkowski, "Some simulations on filler reinforcement in elastomers," Polymer, vol. 46, no. 21, pp. 8894-8904, 2005.

[8] G. Heinrich, M. Kluppel, and T. A. Vilgis, "Reinforcement of elastomers," Current Opinion in Solid State and Materials Science, vol. 6, no. 3, pp. 195-203, 2002.

[9] G. Kraus, "Reinforcement of elastomers by carbon black," Fortschritte der Hochpolymeren-Forschung, vol. 8, p. 155, 1971.

[10] L. Zhang, "Ideal filler for reinforcement of elastomer," in Proceedings of the 9th International Conference on Frontiers of Polymers and Advanced Materials (ICFPAM '07), Poznan, Poland, 2007.

[11] G. Kraus, K. W. Rollmann, and J. T. Gruver, "Dynamic properties of a model reinforced elastomer. Styrene-butadiene reinforced with polystyrene," Macromolecules, vol. 3, no. 1, pp. 92-96, 1970.

[12] M. Morton, "Mechanisms of reinforcement of elastomers by polymeric fillers," Advances in Chemistry Series, vol. 99, pp. 490-509, 1971.

[13] J. J. Cai and R. Salovey, "Model filled rubber IV: dependence of stress-strain relationship on filler particle morphology," Journal of Materials Science, vol. 34, no. 19, pp. 4719-4726, 1999.
[14] J. J. Cai and R. Salovey, "Model filled rubber-part V: mechanical properties of rubbery composites," Journal of Materials Science, vol. 36, no. 16, pp. 3947-3953, 2001.

[15] L. Zheng, A. F. Xie, and J. T. Lean, "Polystyrene nanoparticles with anionically polymerized polybutadiene brushes," Macromolecules, vol. 37, no. 26, pp. 9954-9962, 2004.

[16] X. Wang, J. E. Hall, S. Warren, et al., "Synthesis, characterization, and application of novel polymeric nanoparticles," Macromolecules, vol. 40, no. 3, pp. 499-508, 2007.

[17] Y.-P. Wu, Y.-Q. Wang, H.-F. Zhang, et al., "Rubber-pristine clay nanocomposites prepared by co-coagulating rubber latex and clay aqueous suspension," Composites Science and Technology, vol. 65, no. 7-8, pp. 1195-1202, 2005.

[18] Y.-Q. Wang, Y.-P. Wu, H.-F. Zhang, L.-Q. Zhang, B. Wang, and Z.-F. Wang, "Free volume of montmorillonite/styrenebutadiene rubber nanocomposites estimated by positron annihilation lifetime spectroscopy," Macromolecular Rapid Communications, vol. 25, no. 23, pp. 1973-1978, 2004.

[19] J. Ma, P. Xiang, Y.-W. Mai, and L.-Q. Zhang, "A novel approach to high performance elastomer by using clay," Macromolecular Rapid Communications, vol. 25, no. 19, pp. 1692-1696, 2004.

[20] L. Zhang, Y. Wu, Y. Wang, et al., "Nano-reinforcing and nanocompounding technique of rubber," China Synthetic Rubber Industry, vol. 23, no. 2, pp. 71-77, 2000.

[21] L. Zhang, Z. Wang, Y. Wu, and S. Wu, "Percolation phenomena and mechanism in rubber reinforcement with different nano fillers," China Synthetic Rubber Industry, vol. 31, no. 4, p. 245, 2008.

[22] G. R. Hamed, "Reinforcement of rubber," Rubber Chemistry and Technology, vol. 73, no. 3, pp. 524-533, 2000.

[23] J. Liu, D. Cao, L. Zhang, and W. Wang, "Time-temperature and time-concentration superposition of nanofilled elastomers: a molecular dynamics study," Macromolecules, vol. 42, no. 7, pp. 2831-2842, 2009.

[24] Z. H. Wang, J. Liu, S. Z. Wu, W. C. Wang, and L. Q. Zhang, "Novel percolation phenomena and mechanism of strengthening elastomers by nanofillers," Physical Chemistry, Chemical Physics, vol. 12, pp. 3014-3030, 2010.

[25] A. R. Payne, "The dynamic properties of carbon black-loaded natural rubber vulcanizates," Journal of Applied Polymer Science, vol. 6, pp. 57-63, 1962. 



The Scientific World Journal

Submit your manuscripts at

http://www.hindawi.com

\section{World Journal}

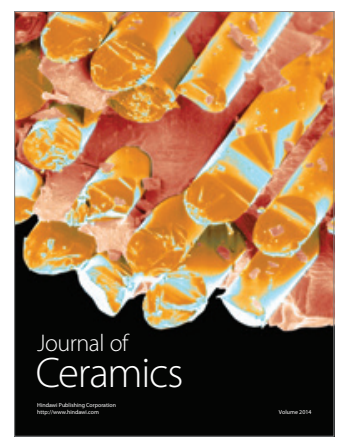

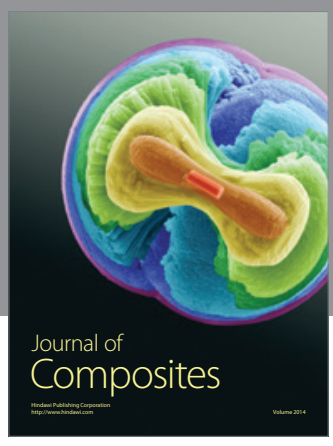
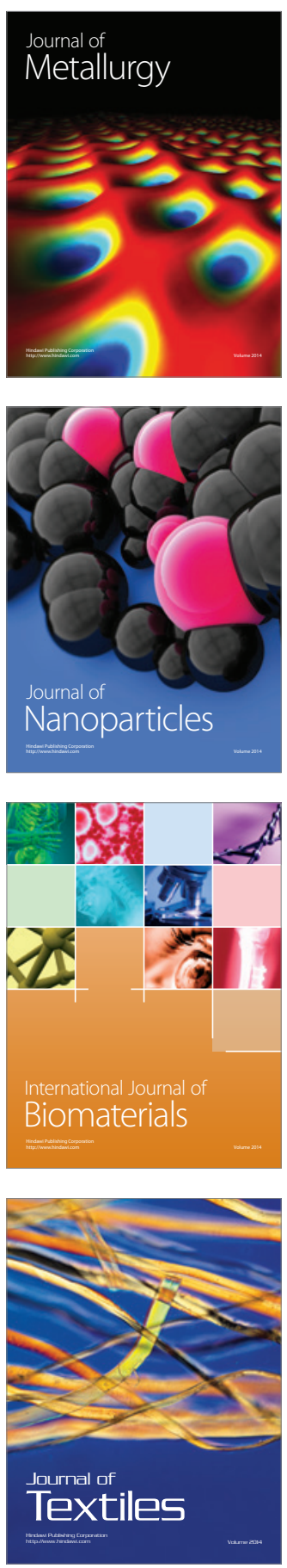